\title{
Anesthesia New Century-0ptiflow in Anesthesia- You may use NMJB without Endotracheal Tube or LMA and only with Nasal Cannula
}

\author{
Cheesang Ho* \\ Anesthesia Department, Kuang Tien General Hospital, Taiwan
}

Submission: March 16, 2018; Published: March 23, 2018

*Corresponding author: Cheesang Ho, Anesthesia Department, Kuang Tien General Hospital, Anesthesia Department, Taipei Medical University, 117 Shatian Road Shalu District, Taichung City 43303, Taiwan, Tel: 886 937185868; Email: b611071@tmu.edu.tw

Abstract

Optiflow was wide used in internal medicine and pediatric. In anesthesia, there were many paper in publish about high-flow nasal oxygen optimizes preoxygenation and apnea time compared with low-flow techniques, and improves carbon dioxide $\left(\mathrm{CO}_{2}\right)$ clearance and enhanced apnea time, but no any paper to description using Optiflow in anesthesia. In this paper will be described how to use Optiflow in anesthesia and its principle and mechanism, benefits and limitation.

Keywords: Optiflow anesthesia; Low airway pressure; High flow; Nasal cannula

\section{Introduction}

What is Optiflow? Optiflow is word optimal flow, which was provided by Fisher \& Paykel Healthcare in 20 years ago. Optiflow device could provide ability to independently titrate $\mathrm{FiO}_{2}$ (up to $100 \%$ ) and flow up to $60 \mathrm{~L} / \mathrm{min}$. In respiratory therapy, which was a revolutionary therapy and one of the most exciting developments since the introduction of noninvasive ventilation? In internal medicine, the physicists used this device to treat central sleep apnea and COPD, respiratory failure and heart failure patient instead of CPAP [1-4]. In recent years there were some publication about Optiflow could enhance the apnea time for intubation and also increased the outcome in postextubation [5]. But there were no any publication about Optiflow in anesthesia. Does it could be used in anesthesia? That is a good question.

\section{Optiflow in internal medicine}

Since Optiflow device was in marketing, the physician used it instead CPAP for COPD [1-4] and heart failure [6], sleep apnea syndrome $[7,8]$ and in newborn infants [9].

\section{The benefits of Optiflow}

There were three kinds of benefits including caregivers, patients and hospitals.

\section{For Caregivers}

a. Reduced need to change between multiple oxygen devices
b. Accurate oxygen delivery
c. Improved respiratory efficiency
d. Effective postextubation support
e. Reduced escalation of care

\section{For Patients}
a. $\quad$ Reduced need to wear a face mask
b. Able to eat, drink and talk while receiving therapy
c. More comfortable
d. Full moveable

\section{For Hospitals}
a. Potential reduction in number of ventilator days
b. Potential reduction in length of stay in ICU
c. Cost down
d. Satisfaction enhancement

\section{Optiflow in anesthesia, does it can?}

Everybody knows that the oxygen could not transfer to the brain directly, because of the brain was protected by the skin and the skull bone. And the oxygenation must be done by the respiration system. The mechanism of respiration was by diffusion and bulk flow. Every time, at rest breathing, approximately one 
third of tidal volume is breathe in from the anatomical dead space. The anatomy dead space in adult is about $150 \mathrm{ml}(2.2 \mathrm{mLs} / \mathrm{kg})$ [10], and the alveolar dead space [10] is sum of the volumes of those alveoli which have little or no blood flowing through their adjacent pulmonary capillaries, i.e., alveoli that are ventilated but not perfused, and where, as a result, no gas exchange can occur Alveolar dead space is negligible in healthy individuals, but can increase dramatically in some lung diseases due to ventilationperfusion mismatch. This was about $24 \mathrm{ml}$. The diffusion, we can not to control it, but the rebreathing gas in dead space we could control. Normally, we need inspiration and expiration to reduce the dead $\mathrm{CO}_{2}$. But now we used high volume bulk flow, the dead space $\mathrm{CO}_{2}$ will be changed to be oxygen, a nearly $100 \%$ oxygen in dead space. Which significantly reduce $\mathrm{CO}_{2}$ rebreathing due to HFNC, approximately $1.8 \mathrm{cc} /$ second increased in clearance for every $1.0 \mathrm{~L} / \mathrm{min}$ increase in flow? Because of that, we may use neuromuscular junction blocker (NMJB) without endotracheal tube or LMA and only with nasal cannula (Figures 1-3).

- Diffusion

- Bulk flow

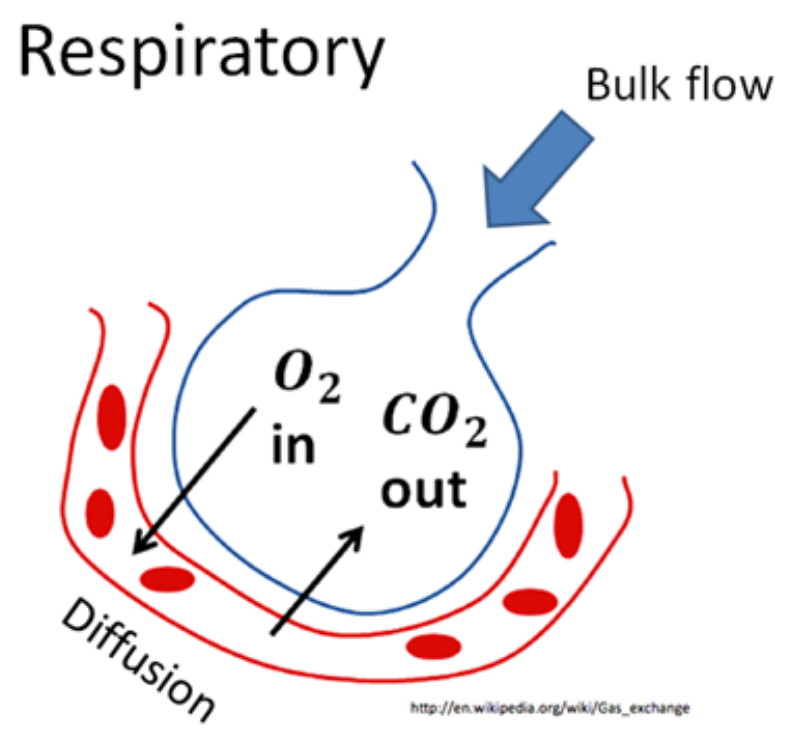

Figure 1: The mechanism of respiration.

\section{Low flow VS High flow}

\section{Apneic Oxygenation using Low-flow oxygen: Laminar flow}

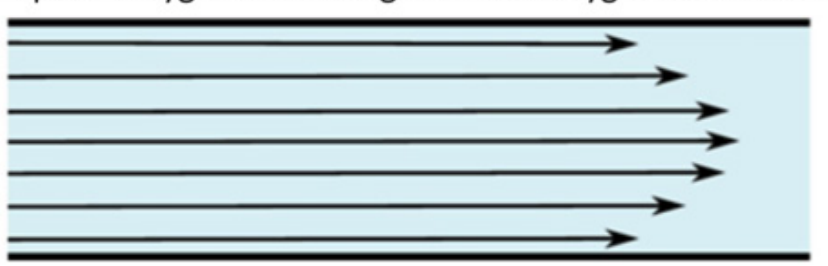

Apneic Oxygenation using High-flow oxygen: Turbulent flow
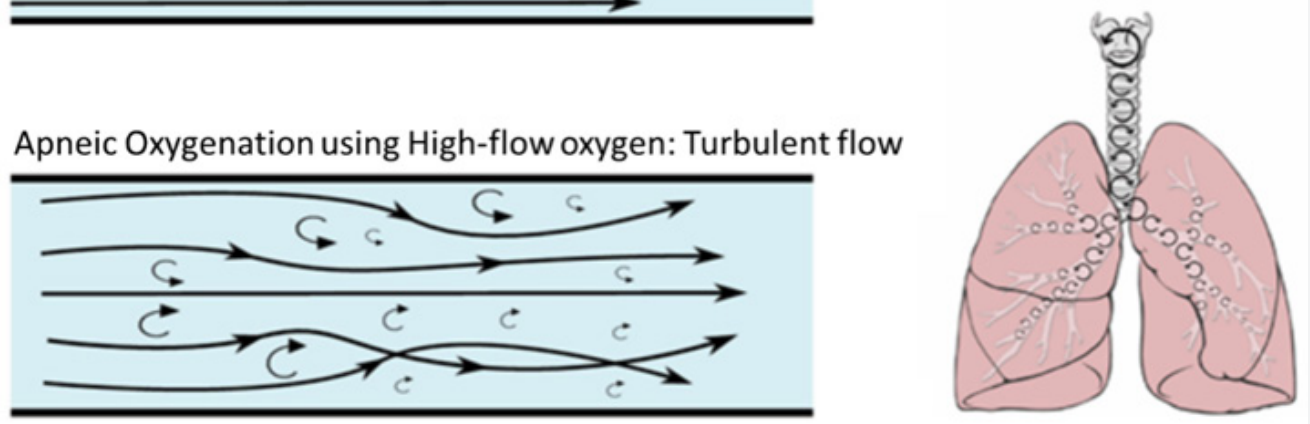

Figure 2: Low flow VS High flow. 


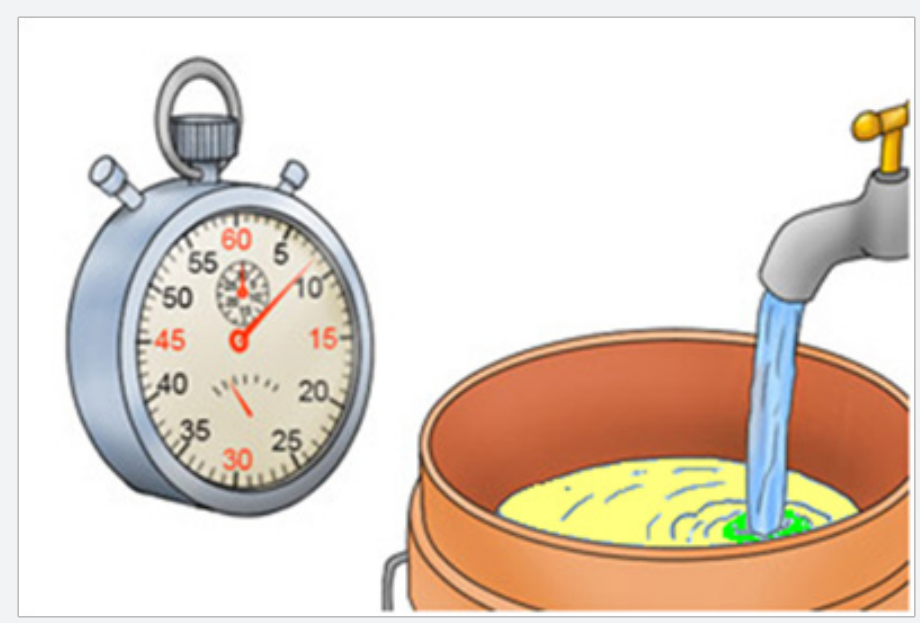

Figure 3: The principle of dead space $\mathrm{CO}_{2}$ wash out due to the volume and time. The bucket volume is a constant, when the flow increased, the time will decrease. As that, when the oxygen flow increased (using high flow), the dead space will be fully filled with oxygen earlier $T_{1} F_{1}$ $=\mathrm{T}_{2} \mathrm{~F}_{2}$.

\section{Optiflow is more effective than traditional oxygen delivery devices in}
a. Improved patient comfort and tolerance
b. Greater therapy success than with face masks
c. Improved lung volumes
d. Improved respiratory rates
e. Improved oxygenation with fewer desaturations
f. Optimized mucociliary clearance

\section{Is all Optiflow device could be used in anesthesia?}

In Fisher \& Paykel Healthcare, they provided two types of humidifier, one is home humidification and the other is hospital humidification. In hospital humidification, there were only MR810 Heated Humidifier and MR850 Heated Humidifier could be used in anesthesia. It was because of those model could provide $100 \%$ oxygen, invasive and noninvasive ventilation and the others were not.

\section{The benefits of Optiflow in anesthesia}

\section{Heated and humidified oxygen with constant concentration}

a. Inhaling dry and cold oxygen provokes upper airway dryness frequently leading to intolerance, and potentially impairing mucociliary function $[11,12]$.

b. Conventional oxygen delivers exceeding $6 \mathrm{~L} / \mathrm{min}$ can lead to insufficient nasal mucosa, even when a cold bubble humidifier is used $[11,12]$.

\section{Positive pharyngeal pressure [13]}

a. Depends primarily upon the flow rate provided by HFNC but also upon the expiratory flow exhaled by the patient.

b. Maintain a steady level of positive pressure during the whole cycle of breath. Parke et al. reported that HFNC increased the mean pharyngeal pressure by about: $1 \mathrm{~cm} \mathrm{H} 2 \mathrm{O}$ per $10 \mathrm{~L} / \mathrm{min}$, within a range of 30-100 L/min.

c. At rest breathing, approximately one third of tidal volume is rebreathed from the anatomical dead space.

d. Significantly reduce $\mathrm{CO}_{2}$ rebreathing due to $\mathrm{HFNC}$, approximately $1.8 \mathrm{cc} / \mathrm{s}$ increase in clearance for every $1.0 \mathrm{~L} /$ min increase in flow.

\section{How does the dead space gas washout?}

Apneic oxygenation using low-flow oxygen is laminar flow, and the apneic oxygenation using high-flow oxygen is turbulent flow, so that the dead space $\mathrm{CO}_{2}$ could be washout [14]. For easily understand, I give a simple study to explain. When you have a bucket of sea water, you used tap water to dilution it (Figure 3). Even you used low flow with long time or used high flow in short time, the sea water must be dilution to be nearly to tap water. So that, when you used high flow the dead space $\mathrm{CO}_{2}$ could nearly totally wash out.

\section{How does the respiration going on?}

In the dead space $\mathrm{CO}_{2}$ was exchanged by oxygen, every inspiration only with the minimal $\mathrm{CO}_{2}$. So that, even the lung no ventilation, the diffusion was going on, and the patient without any hypoxia. This phenomenon you may use brain function monitor (Production by Masimo Company) to monitoring the $\mathrm{SpO}_{2}$, which could monitoring $\mathrm{SpO}_{2}$ from $100 \%$ to $400 \%$.

\section{How we can use Optiflow in anesthesia?}

We must remember that, when you used Optiflow in anesthesia, you could not use inhalation agents, because the flow is too high, if you use that, the outcome is very horrible. And the concentration of inhalation agents you could not easily to control. So, you only could use TIVA/TCI for hypnosis and analgesia. Before induction, you may give the flow about $30 \mathrm{~L} / \mathrm{min}$ for 10 minutes; then you may run TCI. When the patient in sleep, you may adjust 
the oxygen flow to be $70 \mathrm{~L} / \mathrm{min}$. At that time you may use NMJB or not. If you do not used NMJB, the flow up to $50 / \mathrm{min}$ is enough.

\section{Is it supported any surgical position?}

Yes, it could, even in prone and lateral position.

\section{Acidosis}

During in spontaneous breathing, the patent with mild acidemia and doesn't need to treat. When in nonspontaneous breathing, the acidemia is worst then in spontaneous breathing patent. Sometimes you may treat with them.

\section{In POR}

When a patient in POR needs reintubation, we can use Optiflow to instead.

\section{Indication}

All kind of surgery even the patient is in critical state beside contraindication.

\section{Contraindication}

Severe respiratory acidosis. Non-patent nasal passages or facial trauma.

\section{Facial surgery}

Patients who cannot maintain a patent airway. Do not have spontaneous respiratory effort. Head and/or neck injury which has not yet been stabilized. Active hemorrhage with hemodynamic instability. Oral surgery needs electric cauterization.
a. Laparoscopic surgery.
b. Open heart surgery.
c. Transplantation surgery.

\section{Conclusion}

Used Optiflow in anesthesia was innovative and exciting, which could reduce perioperative mortality and morbidity. We could use Optiflow in most of surgery.

\section{References}

1. Fraser JF, Spooner AJ, Dunster KR, Anstey CN, Corley A (2016) Nasal high flow oxygen therapy in patients with COPD reduces respiratory

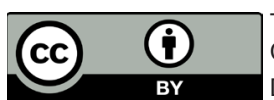

This work is licensed under Creative Commons Attribution 4.0 License DOI: 10.19080/JAICM.2018.06.555682 rate and tissue carbon dioxide while increasing tidal and endexpiratory lung volumes: a randomized crossover trial. Thorax 71(8): 759-761.

2. Saeed AM, Wagih KM, Hussein NA (2015) Evaluation of nasal optiflow device in the management of chronic obstructive pulmonary disease patients with acute exacerbations. Egypt J Bronchol 9(1): 34-42.

3. Saeed A, Wagih K, Huusein N (2015) Evaluation of nasal optiflow device in management of COPD patients in acute exacerbations. European Respiratory Journal 46: PA2170.

4. Dovle AJ (2016) Preoxygenation and apneic oxygenation using transnasal humidified rapid-insufflation ventilator exchange for emergency intubation. J Crit care 36: 8-12.

5. Frat JP, Thille AW, Alain Mercat, Christophe Girault, Stéphanie Ragot, et al. (2015) High-Flow Oxygen through Nasal Cannula in Acute Hypoxemic Respiratory Failure. N Engl J Med 372: 2185-2196.

6. Perales JMC, Llorens $\mathrm{P}$, Brouzet B, Albert JAR, Fernández CJM, et al. (2011) High-Flow Therapy via Nasal Cannula in Acute Heart Failure, Rev Esp Cardiol 64(8): 723-725.

7. Okuda M, Kashio M, Tanaka N, Matsumoto T, Ishihara S, et al. (2014) Nasal high-flow oxygen therapy system for improving sleep-related hypoventilation in chronic obstructive pulmonary disease: a case report. J Med Case Rep 8: 341.

8. McGinley B, Halbower A, Schwartz AR, Smith PL, Patil SP, et al. (2009) Effect of a high-flow open nasal cannula system on obstructive sleep apnea in children. Pediatrics 124(1): 179-188.

9. Ignacio L, Al Faleh K (2014) High-flow Nasal Cannulae in Very Preterm Infants after Extubation. J Clin Neonatol 3(1): 11-13.

10. EM Williams, RM Hamilton, Sutton L, Viale JP, Hahn CEW (1997) Alveolar and dead space volume measured by oscillations of Inspired oxygen in awake adults. Am J Respir Crit Care Med 156(6): 1834-1839.

11. Chanques G, Constantin JM, Sauter M, Jung B, Sebbane M, et al. (2009) Discomfort associated with under humidified high-flow oxygen therapy in critically ill patients. Intensive Care Med 35(6): 996-1003.

12. Cuquemelle E, Pham T, Papon JF, Louis B, Danin PE, et al. (2012) Heated and humidified high-flow oxygen therapy reduces discomfort during hypoxemic respiratory failure. Respir Care 57: 1571-1577.

13. Chen L, Li HL, Laurent (2016) High-flow nasal cannula in postextubation management. J Thorac Dis 8(9): E1013-E1016.

14. Garg R, Gupta RC (2013) Analysis of Oxygen, Anaesthesia Agent and Flows in Anaesthesia Machine. Indian J Anaesth 57(5): 481-488.

Your next submission with Juniper Publishers
will reach you the below assets
- Quality Editorial service
- Swift Peer Review
- Reprints availability
- E-prints Service
- Manuscript Podcast for convenient understanding
- Global attainment for your research
- Manuscript accessibility in different formats
( Pdf, E-pub, Full Text, Audio)
- Unceasing customer service
Track the below URL for one-step submission
https://juniperpublishers.com/online-submission.php

